\title{
Analysis of Substitutes for Improving Healthcare Facilities to Combat Against COVID-19
}

\author{
Ar. Khushnuma Parveen ${ }^{1}$ \\ ${ }^{1}$ Student- M.Arch $2^{\text {nd }}$ Yr., \\ Faculty of Architecture and Ekistics \\ Jamia Millia Islamia \\ New Delhi, India
}

\author{
Ar. Shabnam Khan ${ }^{2}$ \\ ${ }^{2}$ Student- M.Arch $2^{\text {nd }}$ Yr., \\ Faculty of Architecture and Ekistics \\ Jamia Millia Islamia \\ New Delhi, India
}

\begin{abstract}
Abtract-Health is a fundamental human right and a worldwide social goal. The novel coronavirus pandemic outbreak have its severe impact on population growth and the healthcare sector all over the world. As the virus spread across continents, it is clear that the new normal called new approaches in hospitals buildings design and architecture. As the number of beds are not sufficient enough for the growing number of coronavirus cases in India (and worldwide) so here's come the need for alternatives solutions for improving healthcare facilities that can provide healthcare services to those who are in urgent need. It will help to minimizing the load on hospitals and fulfill the need of bed shortage. This paper will discuss about the various substitutes for improving healthcare facilities to combat against covid19.
\end{abstract}

Keywords-Covid19, impact, response, substitute solutions, temporary healthcare operations.

\section{INTRODUCTION}

Outbreaks have been occurring frequently, but every outbreak does not reach a global pandemic level as the Novel Coronavirus (COVID-19) has. COVID-19 affects different people in different ways. Pandemics are large-scale outbreaks of infectious disease with high burden of morbidity and mortality over a wide geographic area and cause significant economic, social, and political disruption. Globalization, with increased global integration \& travel, urbanization, and greater exploitation of the natural environment, has led to pandemics spreading quickly, with COVID-19 being deadliest of all witnessed in our lifetimes thus far. With over 100 countries worldwide now dealing with the impacts of COVID-19, significant pressure has been placed on critical medical supplies (masks,gear, ventilators etc.), healthcare facilities \& hospital staff.

America Makes, ConquerCOVID19 in Canada and CECIMO, the European organization for additive manufacturing and machine tool production) and producers have leveraged their collective resources to offer innovative solutions that alleviate the strains on medical equipment as well as to ensure front line workers stay safe.

Modern hospitals often lack the flexibility to accommodate a sudden surge of patients. In particular, many hospitals have been running out of space and resources to treat COVID-19 patients with severe symptoms, while at the same time handling those with mild symptoms and the asymptomatic who may infect health care workers and other patients.

As the virus spread across continents, it is clear that the new normal called new approaches in hospitals buildings design and architecture. As the number of beds are not sufficient enough to cater the growing number of coronavirus cases in India (and worldwide) so here's come the need for alternatives solutions for healthcare facilities that can provide healthcare services to those who are in urgent need. This will help in minimizing the load on hospitals and the medical staff.

For this purpose, the workforce start identifying alternate sites suitable for patient care such as convention centers, sports arenas, community centers, hotels, dormitories and other spaces to be used for temporary healthcare operations during a pandemic. The COVID-19 pandemic is also exposing new needs for hospitals that neither open wards nor more flexible capacity can address. For instance, hospital designers and architects are discussing the need for touchfree control for lighting, temperature, and other building functions, to help avoid spreading diseases on these highly used surfaces.

\section{BACKGROUND AND SIGNIFICANCE OF STUDY:}

In 2003, the SARS outbreak in Hong Kong became a global threat affecting 30 countries. At that time too, people at the greatest risk were health workers exposed to the patients or by procedures such as intubation, aerosolized medication and laboratory people handling human secretions. A study on healthcare workers exposed to SARS-CoV patients made a shocking revelation that $56 \%(n=80)$ of them were found to be asymptomatically infected even while using N95 masks, gloves and gowns. Further, in the case of SARS-CoV in Hong Kong, the frontline health workers were found with psychological stress and formed as much as thirty percent of the total infected population.

India's public health spending is less than 1 per cent of the country's GDP, which is lower than some of its neighbors, countries such as Bhutan (2.5 per cent), Sri Lanka (1.6 per cent) and Nepal (1.1 per cent). In fact, according to the World Health Organisation, India finishes second from the bottom amongst the 10 countries of its region for its percentage spending of GDP on public health. Maldives spends 9.4 per cent of its GDP to claim the top spot in the list, followed by Thailand ( 2.9 per cent). India has a severe shortage of healthcare workers. According to the Health Ministry data released in October last year, there is one doctor for every 11,082 people, which is more than 10 times the doctor-patient ratio that the World Health Organization (WHO). The WHO mandates that the doctor to population ratio should be 1:1,000, while India had a 1:1,404 ratio as of February 2020. In rural areas, this doctor-patient ratio is as low as 1:10,926 doctors as per National Health Profile 2019 
Similar trends for India are observed on indicators like hospital beds per 1,000 people. As per the OECD data available for 2017, India reportedly has only 0.53 beds available per 1,000 people as against 0.87 in Bangladesh, 2.11 in Chile, 1.38 in Mexico, 4.34 in China and 8.05 in Russia. The numbers have not changed in the last four years. Until recently, India had only 111 Covid-19 testing centers to handle a population of 1.35 billion people. The number of beds in government-run quarantine facilities across the country, meanwhile, is about 60,000.

We don't have that scale of availability of patient beds or ICU beds, or ventilators, which might be required if the worst case scenario happens.

The main objective is:

- To propose an idea of mobilization and creating effective space.

- Cost-effective rooms and ICUs and to make fast approach to take care of the patients infected by the corona virus.

- How to provide better spacing in waiting areas and improve ventilation.

- Build easily and sustainable and fit for the purpose that can also be adapted to treat new diseases and emergencies.

\section{ALTERNATIVE CONCEPTUAL IDEAS WHICH ARE USED FOR TEMPORARY HEALTHCARE OPERATIONS DURING A PANDEMIC:}

In order to provide better healthcare service during the pandemic, many alternatives ways have been adopted for minimizing the load on healthcare structure.

Alternative solutions are provided in different ways, ranging from the simple repurposing of existing spaces, to the wholesale gut renovation and/or expansion of departments, addition of service lines or the complete replacement of a given infrastructure.

\section{A. Railway Coached Converted as Covid Care Level 1 Centers.}

So far, 5,321 non-AC sleeper class coaches of ICF variety (older design) have been converted by the 16 zonal railways through their workshops spread across India. These are developed as COVID Care Level 1 centers - as per the Health Ministry classification of COVID facilities - where suspected cases or those with mild symptoms are to be kept. Suspected and confirmed cases will be kept in separate coaches.

\section{How were these coaches selected?}

Early into the pandemic health experts were of the view that air-conditioned environments might aid the spread of the virus. Well-ventilated, airy environments were thought to be safer.

India's decision to use non-AC coaches for isolation has to be viewed in that context. As per targets given to the 16 zonal railways, 5,000 older coaches, surplus to Railways' operational needs, were marked for conversion. With each carrying 16 patients, this translates into 80,000 isolation/quarantine beds. Railways said it has set aside
20,000 coaches and if needed, more conversions can be done.

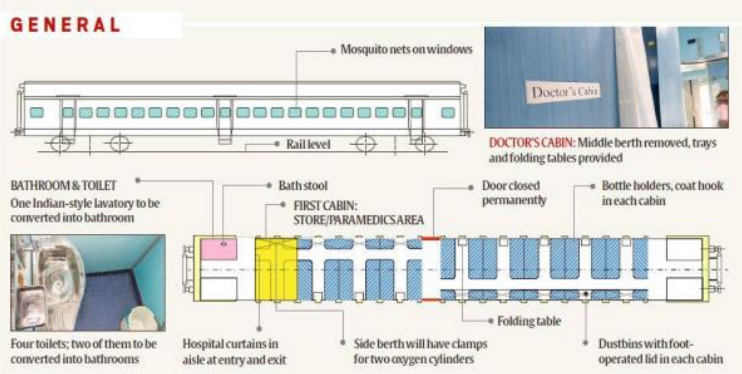

Fig.1 showing layout of railway general coach after convert into Covid Care Level 1 Center.

\section{How were they converted?}

Each sleeper coach is divided into eight bays or "cabins". The idea was to remove the middle berths so that each bay carries two patients on the lower berths - a capacity of 16 per coach. Two of the four toilets were converted into bathrooms.

The windows were covered with mosquito nets. Power plug sockets were installed for medical equipment in each bay. And plastic curtains were installed in every cabin. Each coach also has oxygen cylinders.

Each coach has been converted at a cost around Rs 2 lakh. So the 5,321 coaches have been converted at over Rs 100 crore.

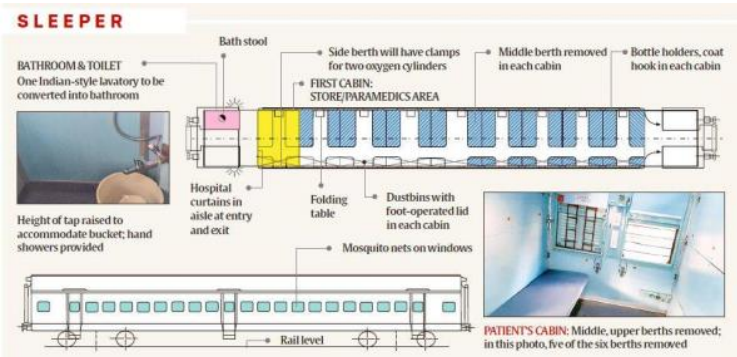

Fig.2 showing layout of railway sleeper coach after convert into Covid Care Level 1 Center.

3. What were the challenges faced?

The summer heat in the coach was always a matter of discussion, not only in Railways but also in the Empowered Group of Secretaries based on whose inputs the coaches were converted.

Several ideas were discussed, including erecting shamianas over the coaches, or painting the roof with "solar reflective" paints.

Finally, it was decided the roof would be insulated in a number of coaches. The technical solution was vetted by the Research Designs and Standards Organisation of Railways. A solution has been developed by IIT Mumbai which brings down the temperature in the coach by several degrees. Railways has attached an AC coach as well, for doctors and medical staff.

How to dispose of toilet waste if the coaches were in remote areas and whether such waste was potentially infectious. It was agreed that since chlorine tablets are placed in the chambers of the bio toilets, the risk was neutralized. In any 
case, bio-enzymes in the toilet tanks take care of the human waste.

Another question was placement. The batteries of the coaches need to be charged and the water needs to be replenished. The idea was that being mobile units, they could be dispatched to any part of the country to pick up patients and come back to their bases.

4. Will these be upgraded further?

NITI Aayog in early May proposed that instead of mere COVID Care Level 1 centres, some of these coaches should be upgraded to hospitals, with oxygen, ICU and ventilator facilities.

It was also suggested that Railways could take help from private hospitals for the upgrade. In a meeting with Railways, NITI Member V K Paul, who is also the head of the relevant Empowered Committee, suggested that the coaches be upgraded to Level II and III COVID Care Centres.

Railways discussed internally that such a task would require months. One rake of Lifeline Express, which is "hospital on wheels" with all medical facilities, takes months to roll out.

\section{B. 5-Star Hotels being converted into Quarantine Centre:}

The capital city of India, New Delhi have the highest number of coronavirus cases after Mumbai and this number is increasing day by day so in order to fulfill the growing demands and to provide healthcare facilities few hotels in new Delhi are being converted into quarantine centers.

These hotels shall provide regular services, including rooms, food, housekeeping and disinfection, to patients at a price not more than ₹ 5,000 for five-star hotels and ₹ 4,000 for four-star or three-star hotels per person per day. After Mumbai, five Delhi hotels have been converted into makeshift COVID-19 hospitals and quarantine centres that provide all necessary healthcare facilities these are:

- Hotel Siddhartha,

- Crowne Plaza(25 hospital beds),

- The Surya (50 hospital beds),

- Hotel Jivitesh, and

- Hotel Sheraton

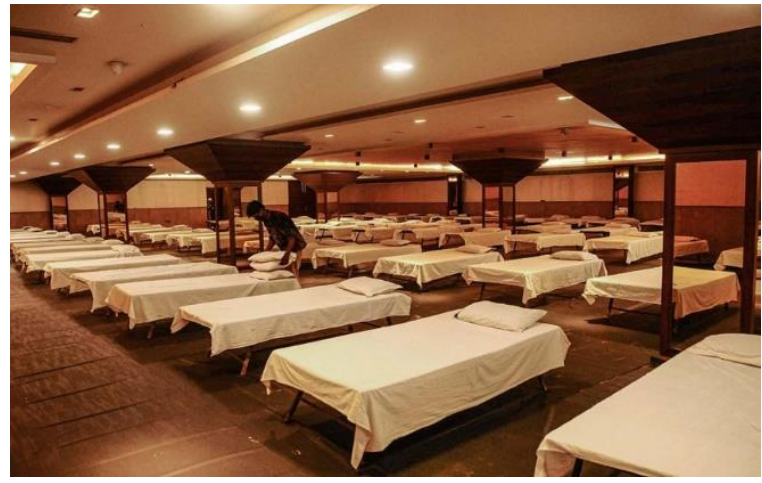

Fig.3 showing layout of beds in quarantine center of surya hotel

Five-star deluxe Hotel Suryaa of New Delhi has been turned into COVID care centre amid coronavirus pandemic. All medical facilities will be made available to the patients in the five-star hotel. The Suryaa Hotel has been attached to the Holy Family Hospital to share the coronavirus caseload and to keep more hospital beds free for severe patients amid a spike in the number of cases in the national capital.

Once admitted, a telephonic assessment of every patient will be done at least once in every twelve hours and physically every day. Even common medical kits like BP regulator, oxygen saturation monitor, thermometers should be available at these facilities. Even ambulances must be available there for $24 * 7$ hours.

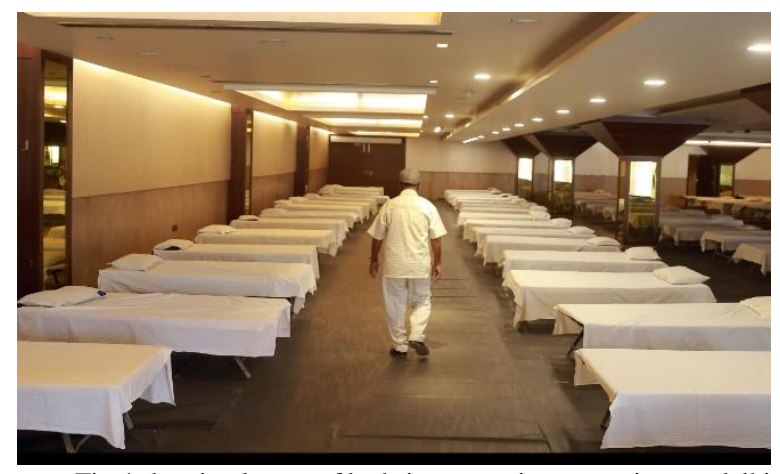

Fig.4 showing layout of beds in quarantine center in new delhi

C. Government schools turned into quarantine facilities: Over 90 Centre-run Kendriya Vidyalayas (KVs) and Jawahar Navodaya Vidyalayas (JNVs) have been turned into quarantine centres across India as part efforts to create additional heathcare infrastructure to deal with any major spike in the number of the coronavirus (Covid-19) cases. In the event of cases of novel coronavirus escalating and spilling over from hospitals, the Delhi government will turn to schools for accommodating suspect and confirmed patients, who need to be isolated.

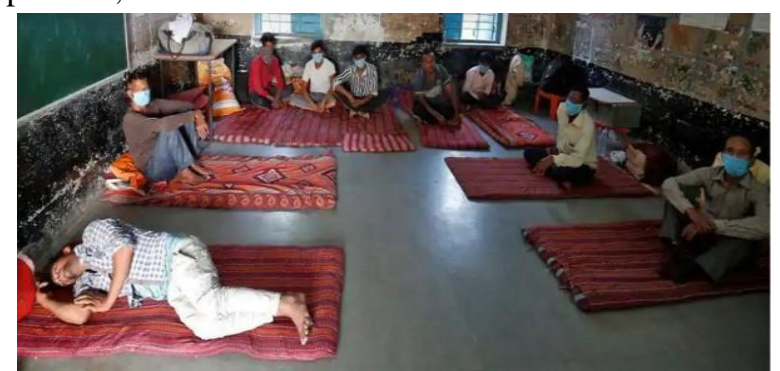

Fig.5 showing people are quarantine $\&$ following social distancing

\section{D. hospital isolation rooms design:}

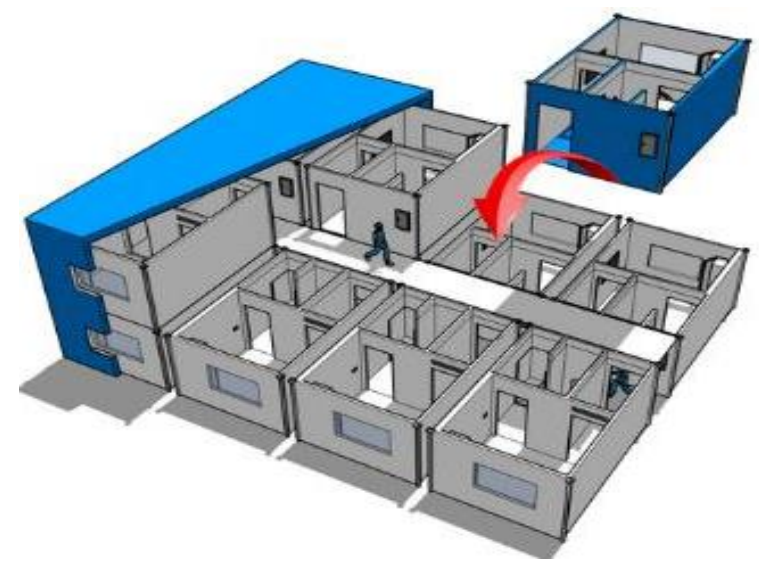




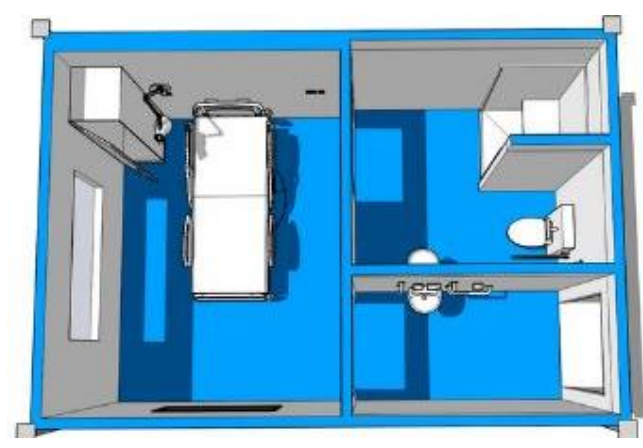

Fig.6 isolation rooms

Negative-pressure isolation rooms are required for quarantined patients with coronavirus to prevent droplets (from sneezing, coughing or exhalation) and contact transmission. To minimize the spread of airborne infection, healthcare facilities have designed airborne infectious isolation (AII) rooms with negative-pressure differential and/or protective environment (PE) rooms with positivepressure differential.

Our smooth modular walls, doors and windows are resistant to repeat cleaning and the use of several chemicals. They also specifically designed for sterile environments. Airflow and heap filters: Just like cleanrooms, isolation rooms require a higher rate of air exchange per hour, typically a minimum of 12 air changes per hour.

For highly infectious patients with pathogens such as hemorrhagic fever and pneumonic plague, 100\% fresh air intake is necessary. No air recirculating is possible.

\section{Positive-Pressurized Protective Environment: HEPA}

filtered air is generally used for positive pressurized rooms to isolate immunocompromised patients, for example in oncology and some transplant patients, to reduce the risk of airborne transmission of infection to the patient. These rooms are known as protective isolation units.

E. Hospitals made from shipping containers could help tackle COVID-19:

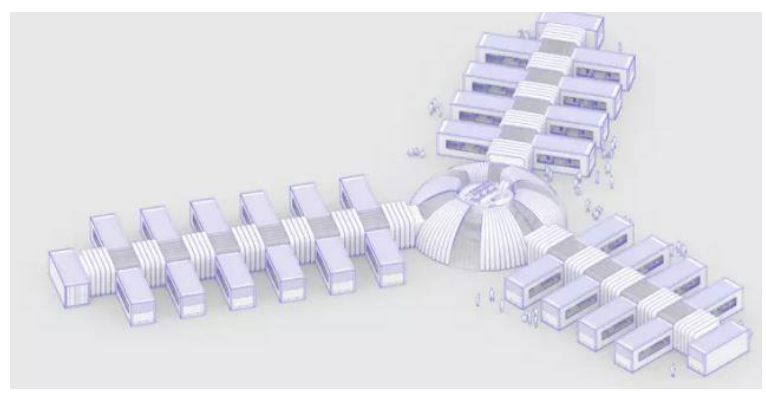

Fig.7 Configuration of a mobile intensive care hospital.

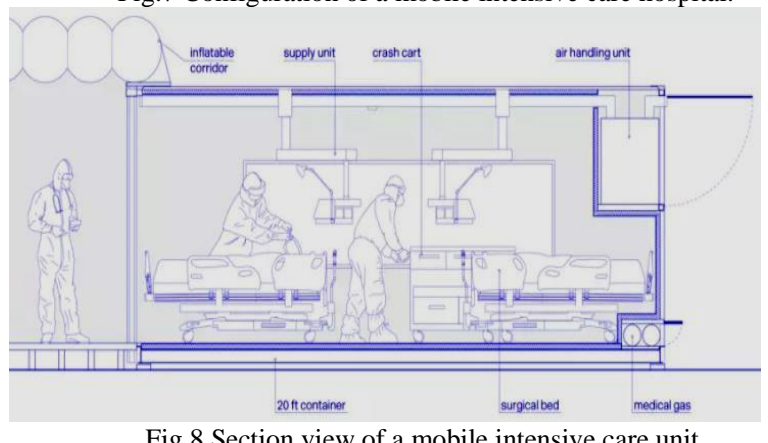

- Architects have designed intensive care units built inside shipping containers.

- These mobile hospitals could help ease pressure on health systems.

- The team behind CURA wants to scale rapidly to tackle the spread of COVID-19 in Africa.

The structure is quick to assemble and disassemble. Because it is made of shipping containers, it can be moved from epicentre to epicentre by road, rail and ship, within countries and from city to city around the world.

There is no international standard requiring a set number of hospital beds per thousand of population, so there are huge differences between countries.

They have teamed up with engineering firms, logistic experts and medical equipment suppliers, as part of a nonprofit effort, to create the Connected Units for Respiratory Ailments, or CURA. These are designed to be as quick as a tent to put up, but as safe as a hospital with "biocontainment" - a series of safety practices to prevent the spread of disease.

\section{E. Patient Screening Booths:}

Patient Screening Booth that keeps medical practitioners protected while examining a large number of patients. Consisting of a transparent partition equipped with sealed gloves.

That maximize healthcare professional's ability to examine patients while reducing exposure and limiting the need for PPE.

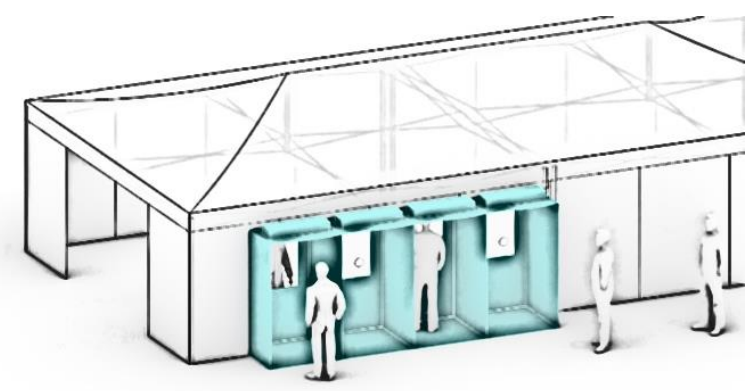

Fig.9 showing patient screening booths.

Healthcare workers are extremely concerned about their personal safety and the safety of their families' walk-in testing booth that intends to keep healthcare professionals safe and limit exposure to the virus during patient screenings.

F. Prefabricated Health Facilities:
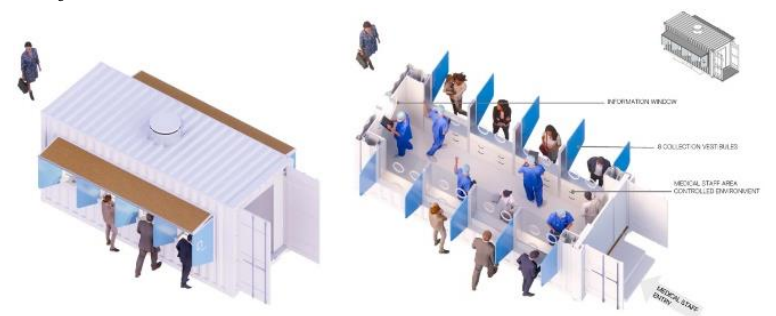

Fig.10 prefabricated structure

Dubbed D-TEC, the deployable structures made of upcycled shipping containers.

Medical staff are inside the facility, separated from patients who approach the exterior. 


\section{"Testing can be done without contact between staff and patient."}

Until we can better understand the virus' pathways, we won't be able to confidently redesign our existing spaces to adhere to new and higher standards of infection control guidelines.

\section{G. Exhibition Centre has been converted into the} temporary NHS Nightingale hospital.

The UK's newest, and largest, hospital facility has taken in its first coronavirus patients needing intensive care treatment. East London's ExCeL exhibition centre, which normally plays host to lifestyle shows, expos and conferences, has been converted into the temporary NHS Nightingale hospital, with space for 4,000 beds.

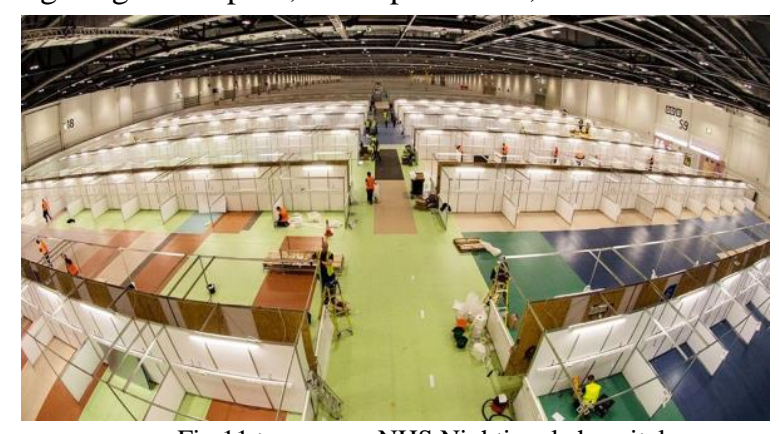

Fig.11 temporary NHS Nightingale hospital

In nine days, the 87,328 square metres of double exhibition halls have been fitted out with the framework for about 80 wards, each with 42 beds. Some 500 fully-equipped beds, with oxygen and ventilators, are already in place and there is space for another 3,500.

Each ward is named after a different British doctor, nurse or other medical professional.

The facility, which was officially opened on 3 April, was built with the help of up to 200 soldiers a day from the Royal Anglian Regiment and Royal Gurkha Rifles, working long shifts alongside NHS staff and contractors. Architects and engineers from BDP, the firm that helped convert the centre, were part of the planning team given the task of creating the life-saving facility.

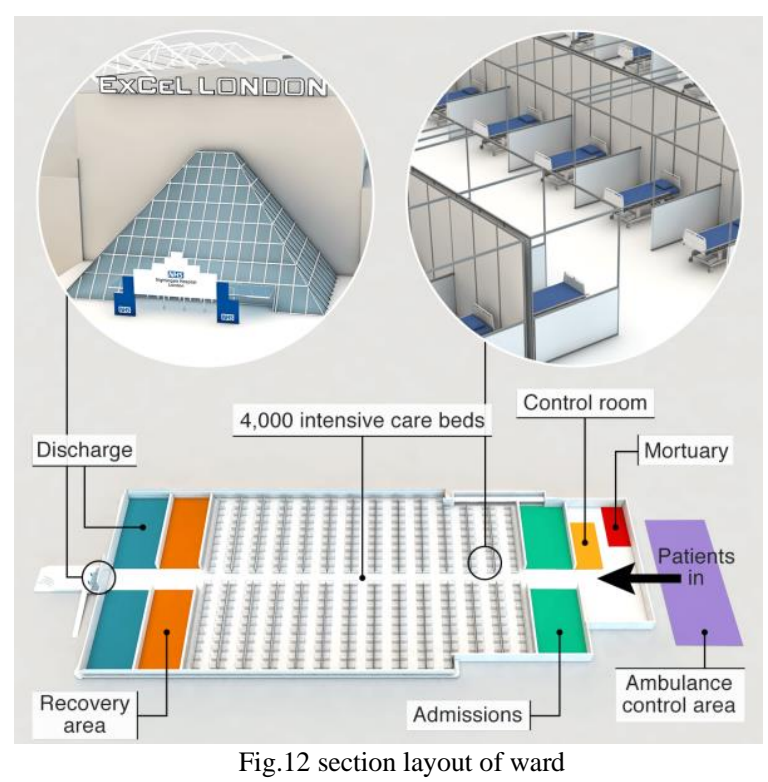

The framework for individual bed bays were made from material usually used to make exhibition stands - because it is lightweight and could be constructed quickly And being able to get medical gases to each of the beds.

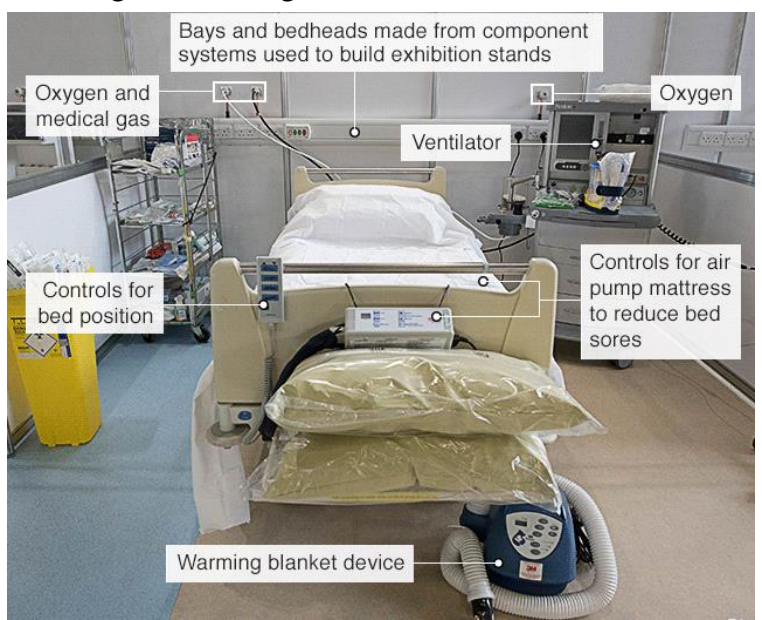

Fig.13 a typical bed bay at nightingale

\section{CONCLUSION:}

The COVID-19 pandemic is now a major global health threat. Emerging pandemics show that humans are not infallible and communities need to be prepared. Coronavirus outbreak was first reported towards the end of 2019 and has now been declared a pandemic by the World Health Organization. Worldwide countries are responding differently to the virus outbreak. A delay in detection and response has been recorded in China, as well as in other major countries, which led to an overburdening of the hospital buildings.

The number of cases increasing day by day all around the world which led to the overburdening of hospitals as the number of beds are not sufficient enough to cater the growing number of coronavirus cases in India (and worldwide) so here's come the need for alternatives solutions for healthcare facilities that can provide healthcare services to those who are in urgent need. This will help in minimizing the load on hospitals and the medical staff.

For this purpose, the workforce start identifying alternate sites suitable for patient care such as convention centers, sports arenas, community centers, hotels, dormitories and other spaces to be used for temporary healthcare operations during a pandemic.

\section{ACKNOWLEGMENT:}

We are thankful to department of architecture at Jamia Millia Islamia University, New Delhi for their support in bringing out this paper successfully.

\section{REFERANCES}

[1] https://www.expresspharma.in/guest-blogs/long-term-impact-ofcovid-19-pandemic-on-healthcare-scenario-in-india/

[2] https://worldarchitecture.org/article-links/efppz/mass-designgroup-redesigns-hospital-spaces-on-the-fly-to-protect-healthcareworkers.html

[3] https://undark.org/2020/04/14/covid-19-india/

[4] https://indianexpress.com/article/explained/railway-station-covidisolation-coaches-coronavirus-patients-anand-vihar-delhi6462371/ 
[5] https://www.medicircle.in/who-helps-reshape-hospitals-covid19eases-grip

[6] https://www.azuremagazine.com/article/design-innovationscovid-19-ppe/

[7] https://www.archdaily.com/937840/alternative-healthcarefacilities-architects-mobilize-their-creativity-in-fight-againstcovid-19

[8] https://www.mecart-cleanrooms.com/applications/isolationsrooms-for-hospitals-covid-19/

[9] https://www.weforum.org/agenda/2020/03/hospitals-shippingcontainers-tackle-covid-19/

[10] HTTPS://www.bbc.com/news/health-52125059 